\title{
Sperm acrosin is responsible for the sperm binding to the egg envelope during fertilization in Japanese quail (Coturnix japonica)
}

\author{
Tomohiro Sasanami, Norio Yoshizaki ${ }^{1}$, Hideo Dohra $^{2}$ and Hideo Kubo ${ }^{3}$ \\ Department of Applied Biological Chemistry, Faculty of Agriculture, Shizuoka University, 836 Ohya, Shizuoka \\ 422-8529, Japan, ${ }^{1}$ Department of Agricultural Science, Gifu University, Gifu 501-1193, Japan, ${ }^{2}$ Institute for Genetic \\ Research and Biotechnology, Shizuoka University, 836 Ohya, Shizuoka 422-8529, Japan and ${ }^{3}$ Department of Medical \\ Biology, Tokyo Metropolitan Institute of Medical Science, Setagaya-ku, Tokyo 156-8506, Japan
}

Correspondence should be addressed to T Sasanami; Email: atsasan@ipc.shizuoka.ac.jp

\begin{abstract}
An antibody library against quail sperm plasma membrane components was established and a mAb, which strongly inhibits sperm perforations of the perivitelline membrane (PVM) was obtained from the library. The antigen molecule of the mAb showed an apparent molecular weight of $45 \mathrm{kDa}$, and was distributed both on the surface and in the acrosomal matrix of the sperm head. Periodate oxidation revealed that the epitope of the antigen includes a sugar moiety. Tandem mass spectrometry analysis of the antigen revealed that the $\mathrm{mAb}$ recognizes sperm acrosin. When sodium dodecyl sulfate-solubilized PVM immobilized on a polyvinylidene difluoride membrane was incubated with sperm plasma membrane lysates, the sperm acrosin was detected on the PVM immobilized on the membrane, indicating that the sperm acrosin interacts with the components of PVM. Indeed, the mAb effectively inhibited the binding of acrosome-intact sperm to the PVM. These results indicate that the $45 \mathrm{kDa}$ sperm acrosin is involved in the binding of sperm to the PVM in fertilization of Japanese quail.

Reproduction (2011) 142 267-276
\end{abstract}

\section{Introduction}

Fertilization is the joining of two gametes, an oocyte and a sperm, and is the consequence of precisely ordered multiple steps, including sperm-egg binding, the induction of the acrosome reaction (AR) on the sperm, and the membrane fusion of the gametes. The zona pellucida (ZP), which is an extracellular matrix surrounding mammalian oocytes, plays an important role in fertilization, especially in the primary binding of the sperm and the induction of the AR as well as preventing polyspermy (Florman \& Ducibella 2006). This matrix is composed of three or four glycoproteins (i.e. ZP1, ZP2, ZP3, and ZP4) in mammalian species (Lefievre et al. 2004, Hoodbhoy et al. 2005, Litscher \& Wassarman 2007, Ganguly et al. 2008, Izquierdo-Rico et al. 2009). In the case of non-mammalian vertebrates such as amphibians (i.e. Xenopus laevis ( $X$. laevis) and Xenopus tropicalis), five ZP glycoproteins (ZPA (ZP2), ZPB (ZP1), ZPC (ZP3), ZPD (ZP4), and ZPAX) have been identified (Lindsay et al. 2003, Goudet et al. 2008). The ZP gene family proteins share a highly conserved amino acid sequence near the C-terminus called the ZP domain, consisting of 260 amino acid residues with eight or ten conserved Cys residues (Bork \& Sander 1992). On the other hand, there are many reports suggesting that the sperm membrane proteins are important for sperm-zona interaction. For instance, the sperm-specific hyaluronidase PH-20 (Primakoff et al. 1988) and Hyal5 (Kim et al. 2005), $\beta-1,4$-galactosyltransferase (Miller et al. 1992) as well as a secreted protein containing $\mathrm{N}$-terminal notchlike type II epidermal growth factor (EGF) repeats and C-terminal discoidin/ F5/8 C domains (SED1; Ensslin \& Shur 2003) have been suggested to be involved in sperm-zona binding in mammalian species, including mice. Other factors in fertilization are thought to compensate for these factors, because disruption of each gene with homozygous null mutation did not make the animals sterile (Ikawa et al. 2008).

In avian species, the perivitelline membrane (PVM), which is the egg envelope homologous to $\mathrm{ZP}$ in mammals, is observed in follicles between granulosa cells and ovum before ovulation (Wyburn et al. 1965). Fertilization occurs within the infundibulum portion of the oviduct, and only the PVM encloses the oocyte at the time of fertilization. Sperm-egg interaction in avian species can be measured in vitro as the ability of the 
sperm to hydrolyze a small hole in the PVM (Kuroki \& Mori 1997, Robertson et al. 1997). Results of this in vitro assay suggested that the $\mathrm{N}$-glycans of the PVM play an indispensable role in sperm-egg interaction and the induction of the AR in domestic fowl (Horrocks et al. 2000, Robertson et al. 2000). Recently, we demonstrated that an N-glycan present on ZP1, one of the major PVM components that are produced in the liver under estrogen control (Sasanami et al. 2003), has the ability to induce the AR in Japanese quail (Sasanami et al. 2007). However, identification of the complementary molecules responsible for the sperm-egg interaction in birds, including the components that interact with ZP1 on the surface of the sperm, remains to be accomplished.

Recently, by the aid of an antibody library raised against the sperm plasma membrane of $X$. laevis (Nagai et al. 2009), Kubo et al. (2010) identified a component that can bind to the vitelline envelope (VE) using a newly developed method, the dot blot assay. As a result, the authors successfully obtained a mAb specific to the sperm membrane protein and showed that the antigen protein interacts with the VE component gp37, a mammalian ZP1 homolog in X. laevis, as shown by farwestern blotting. Although the nature of the antigen protein remains to be uncovered, it appeared to be involved in the sperm-VE binding in the fertilization process of $X$. laevis (Kubo et al. 2010).

The aim of this study was to determine which proteins in the sperm membrane components play a role in fertilization of Japanese quail. To achieve this goal, we produced an antibody library against quail sperm membrane components and tested the potency of the library to inhibit hole formation in the PVM by sperm in vitro. In this paper, we provide the first evidence that sperm acrosin is involved in the sperm-PVM binding in Japanese quail.

\section{Results \\ Effects of mAbs on whole formation by sperm on the PVM}

To obtain an antibody that inhibits fertilization from the antibody library, we tested the potency of each culture supernatant forming the library to block hole formation by sperm in the PVM using an in vitro assay. Of the culture supernatants of the library, as the supernatant 19A was found to block hole formation strongly (data not shown), so we subjected the $19 \mathrm{~A}$ cells to cloning and obtained a hybridoma clone (IgG1 isotype) producing mAb 19A16A13. In Fig. 1, this mAb efficiently blocked hole formation by sperm (panel B) when it was compared with the control (panel A). The purified antibody from the culture supernatant 19A16A13 definitely inhibited hole formation by sperm in a dose-dependent manner (panel C), and the Fab fragment prepared from the purified $\mathrm{mAb}$ also
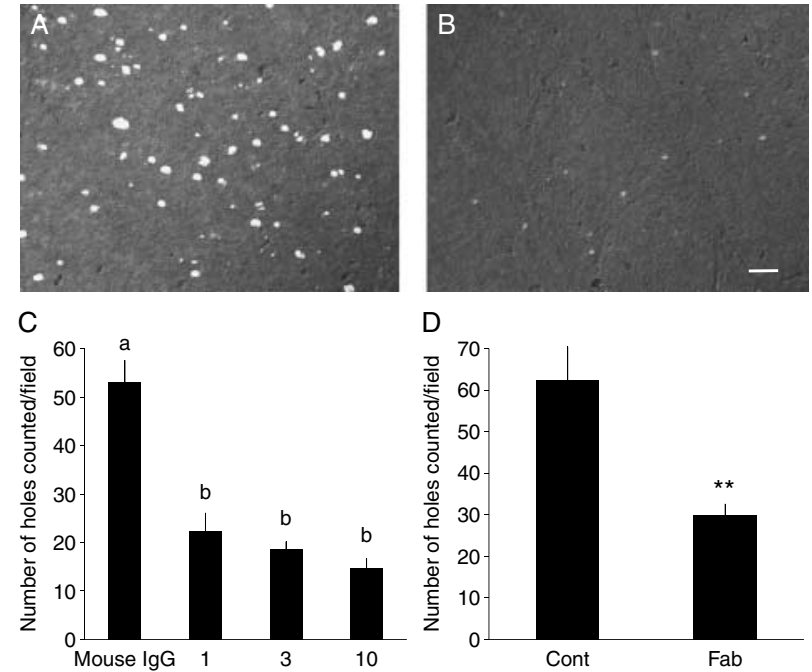

Figure 1 Effects of $\mathrm{mAb}$ on the in vitro formation of holes in the PVM by ejaculated sperm. Ejaculated sperm were incubated with PVM in the presence of the conditioned medium of hybridoma 19A16A13 (panel B) or HAT-supplemented medium alone (panel A) at $39{ }^{\circ} \mathrm{C}$ for $10 \mathrm{~min}$. The PVM was spread on a glass slide, washed with PBS, stained with Schiff's reagent, and observed under a light microscope. Shown are representative photographs of ten independent experiments; scale bar $=100 \mu \mathrm{m}$. (C) Ejaculated sperm were incubated with PVM in the presence of purified mAb 19A16A13 $(1,3$, or $10 \mu \mathrm{g} / \mathrm{ml})$ or mouse lgG $(10 \mu \mathrm{g} / \mathrm{ml})$ at $39^{\circ} \mathrm{C}$ for $10 \mathrm{~min}$, and the number of holes observed in the $\times 400$ field under light microscopy was counted. Data shown are the mean \pm s.D. of three experiments. Values with different superscript letters are significantly different $(P<0.01)$. (D) A Fab fragment was prepared from purified mAb 19A16A13, and ejaculated sperm were incubated with PVM at $39^{\circ} \mathrm{C}$ for $10 \mathrm{~min}$ in the presence of $50 \mu \mathrm{g} / \mathrm{ml}$ Fab fragment (Fab) or vehicle alone (Cont). The number of holes observed in the $\times 400$ field under light microscopy was counted. Data shown are the mean \pm s.D. of three experiments. Asterisks indicate a significant difference, ${ }^{* *} P<0.01$.

significantly blocked the sperm perforation (panel D), indicating that the inhibitory effect of the mAb was not due to a stereophonic hindrance by binding of the $\mathrm{mAb}$, but rather to the direct binding of the $m A b$ to the molecule indispensable for hole formation. These results strongly suggest that the molecule recognized by the mAb 19A16A13 functions in sperm-egg interaction in quail fertilization.

\section{Western blot analysis of the antigen of mAb 19A16A13}

To investigate the nature of the antigen of $m A b$ 19A16A13, we analyzed sperm plasma membrane lysate (SPML) by western blotting. In Fig. 2, the mAb 19A16A13 recognized a $45 \mathrm{kDa}$ protein under non-reducing conditions (lane 1 , in panel A). No band was detected when the blot was incubated with nonspecific mouse IgG (lane 2). The reactivity of the $\mathrm{mAb}$ disappeared when SPML was separated by SDS-PAGE under reducing conditions (lane 1+), indicating that the epitope in the molecule includes disulfide bonds. In addition, since the 

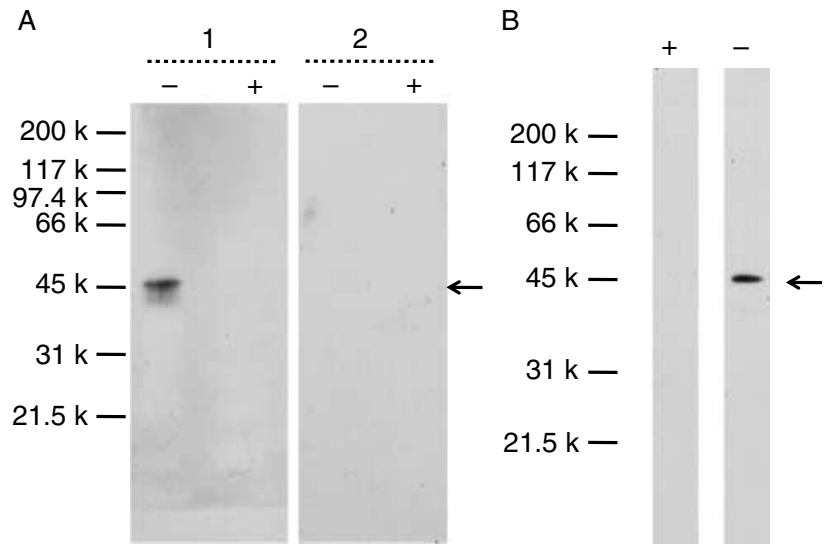

Figure 2 Western blot analysis of SPML with mAb 19A16A13. (A) SPML ( $5 \mu \mathrm{g} /$ lane) was separated by SDS-PAGE under non-reducing (-) or reducing $(+)$ conditions, and the proteins were electrotransferred onto a PVDF membrane. The membrane was probed with mAb 19A16A13 (panel 1, $10 \mu \mathrm{g} / \mathrm{ml}$ ) or mouse lgG (panel 2, $10 \mu \mathrm{g} / \mathrm{ml}$ ). The arrow indicates the immunoreactive band with mAb 19A16A13. (B) SPML (10 $\mu \mathrm{g} /$ lane) was separated by SDS-PAGE under non-reducing conditions, and the proteins were transferred onto a PVDF membrane. Intact $(-)$ and periodate-oxidized $(+)$ strips were subjected to incubation with mAb 19A16A13 $(10 \mu \mathrm{g} / \mathrm{ml})$. The arrow indicates the immunoreactive band with mAb 19A16A13.

immunoreactivity of the $45 \mathrm{kDa}$ protein to the mAb was completely lost when SPML was oxidized with periodate after separation by SDS-PAGE and electrotransfer to a PVDF membrane (panel B, lane + ), we concluded that the $45 \mathrm{kDa}$ protein is a glycoprotein whose sugar moiety is included in the epitope of the mAb 19A16A13. This result indicated that the mAb 19A16A13 reacted with a sugar moiety of the glycoprotein.

\section{Localization of the antigenic $45 \mathrm{kDa}$ protein in sperm}

To analyze the localization of the antigen of the $\mathrm{mAb}$ 19A16A13, $45 \mathrm{kDa}$ protein, we processed ejaculated sperm for immunocytochemical observation (Fig. 3). Immunoreactivity was observed in the anterior head of the sperm (panels A and C). No such signal was observed when nonspecific mouse IgG was used as the primary antibody (panel D). To analyze the localization of the antigen more precisely, we performed immunoelectron microscopy for detection of the antigen on the ultra-thin sections of sperm (Fig. 4). In accordance with the results of the immunocytochemical observations, the immunogold particles were distributed in the acrosomal region of the sperm head (panel B). More importantly, the immunoreactive antigen was found within the acrosome (arrows in panel B) and on the surface of the plasma membrane of the acrosomal region (arrowheads in panel B). No such accumulation of gold particles was observed when the specimens were incubated with control IgG (panel A). These observations demonstrated that the antigen reactive to the $\mathrm{mAb} 19 \mathrm{~A} 16 \mathrm{~A} 13$ specifically localizes in the acrosome region of the sperm head and that this antigen localizes both in the acrosomal matrix and on the surface of the plasma membrane of the sperm head.

\section{Identification of the antigenic $45 \mathrm{kDa}$ protein by tandem mass spectrometry analysis}

To elucidate the nature of the antigen of the $\mathrm{mAb}$ 19A16A13, $45 \mathrm{kDa}$ protein, we separated SPML with two-dimensional SDS-PAGE, and used tandem mass spectrometry (MS/MS) to examine the tryptic fragments of the immunoreactive spot migrating around $45 \mathrm{kDa}$ in molecular weight. Western blot analysis of the proteins separated by two-dimensional SDS-PAGE revealed 45 and $40 \mathrm{kDa}$ spots (arrowheads in panel B). By laying the $X$-ray film on the PVDF membrane stained with Coomassie brilliant blue (CBB) after the chemiluminescent detection, we successfully identified the $45 \mathrm{kDa}$ immunoreactive spots on the CBB stained PVDF membrane, and we excised this spot from CBB stained gel for MS/MS analysis of the antigen (arrowhead in panel A). Using MASCOT MS/MS lons Search, we identified the antigen protein as quail acrosin (GenBank accession number ABQ40000) with a score of 261, and seven peptides corresponding to a sequence coverage of $25 \%$ were matched to the amino acid sequence of quail acrosin (Table 1). MS and MS/MS data were also analyzed by the de novo sequencing and protein identification software PEAKS STUDIO and the sequence tag search tool SPIDER to eliminate false positive results and to improve the sequence coverage.
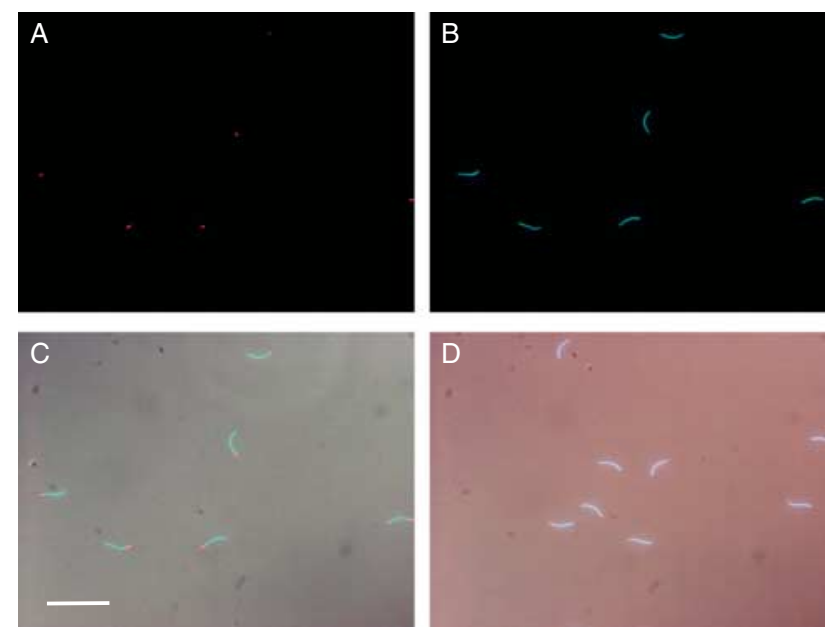

Figure 3 Localization of the antigen of mAb 19A16A13 in ejaculated sperm. The ejaculated sperm were fixed with $3.7 \%(\mathrm{v} / \mathrm{v})$ formalin, and the sperm were spread on glass slides. The specimens were incubated with mAb 19A16A13 $(10 \mu \mathrm{g} / \mathrm{ml})$, and the signals were detected with Texas red-labeled anti-mouse IgG (panel A, 1:200 dilution). The nuclei of the sperm visualized with DAPI are shown (panel B). (C) A merged image of A, B, and DIC is shown. As a control, the mAb 19A16A13 was replaced with mouse $\operatorname{lgG}$ (panel D, $10 \mu \mathrm{g} / \mathrm{ml}$ ); bar $=50 \mu \mathrm{m}$. 

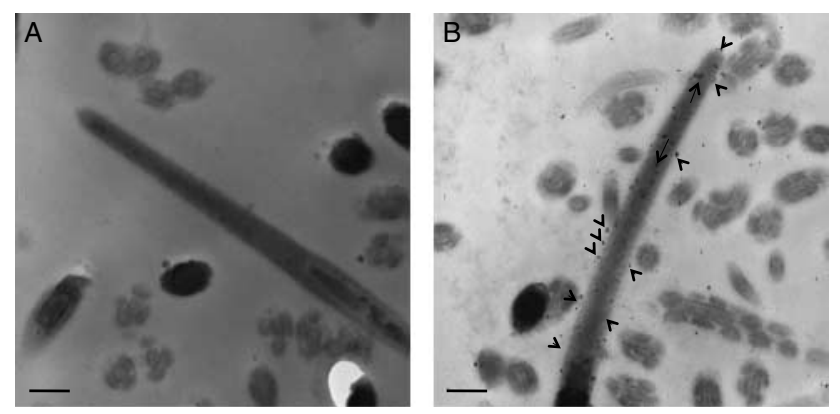

Figure 4 Immunoelectron micrographs of ejaculated sperm. Ultra-thin sections of quail sperm were incubated with mAb 19A16A13 (panel B, $10 \mu \mathrm{g} / \mathrm{ml}$ ) or mouse lgG (panel A, $10 \mu \mathrm{g} / \mathrm{ml}$ ). The accumulation of gold particles was frequently found in the sperm acrosome when the sections were incubated with mAb 19A16A13 (arrows and arrowheads in panel $B$ ), whereas no accumulation was observed on the sections incubated with mouse IgG (panel A). Note that the immunogold particles were localized both on the surface (arrowheads in panel B) and inside (arrows in panel B) of the acrosome. Shown are results representative of repeated experiments; $b a r=500 \mathrm{~nm}$.

The antigen protein was identified as quail acrosin with a high score, and seven and six peptides were matched to the amino acid sequence of acrosin by PEAKS STUDIO and SPIDER respectively (Table 1 ). Results from all search engines used for protein identification were consistent and showed that nine peptides were matched to quail acrosin with a sequence coverage of $31 \%$ in all (Table 1 and Fig. 5C), demonstrating that the antigen reactive to the mAb $19 A 16 A 13$ is quail acrosin.

\section{Effects of mAb 19A16A13 on the proteolytic activity of 45 kDa sperm acrosin}

To examine whether the mAb 19A16A13 can interfere with the proteolytic activity of sperm acrosin, we performed zymography of SPML, as described in the 'Materials and Methods' section. In Fig. 6, the digested protein bands migrating around 60,45 , and $31 \mathrm{kDa}$ showed the proteolytic activity in the control gel strip, which was incubated in the buffer containing $20 \mu \mathrm{g} / \mathrm{ml}$ mouse IgG (lane 1). When the gel strip was incubated with soybean trypsin inhibitor (SBTI; lane 5) or leupeptin (lane 6), known to inhibit the enzymatic activity of sperm acrosin, halo formation in all the bands was inhibited, whereas phenylmethylsulfonyl fluoride (PMSF; lane 4) and bestatin (lane 7) had no effect. Unexpectedly, the incubation of the gel strip with the mAb (lane 2) as well as the Fab fragment of mAb 19A16A13 (lane 3) did not interfere with halo formation. Therefore, the $\mathrm{mAb}$ 19A16A13 was found not to inhibit the proteolytic activity of $45 \mathrm{kDa}$ sperm acrosin itself.

\section{Interaction of sperm acrosin with the PVM}

To characterize the function of the quail sperm acrosin in fertilization, we tested whether the acrosin in SPML interacts with PVM components based on the dot blot assay (Kubo et al. 2010). In Fig. 7, the mAb 19A16A13 recognized immunoreactive acrosin that interacts with the PVM component immobilized on a PVDF membrane. When the PVM and /or SPML were omitted from the assay, the immunoreactive signal was diminished to a background level or lower, indicating the specificity and the reliability of the assay performed here. Next, we tested whether the mAb 19A16A13 was able to block the sperm-egg binding directly. We incubated ejaculated sperm with PVM in the presence of pertussis toxin, which inhibits sperm AR in quail sperm (Sasanami et al. 2007). We found numerous sperm attached to the surface of the PVM after incubation in the absence of the mAb (Fig. 8A), but the attachment was effectively inhibited when the $\mathrm{mAb}$ was added to the reaction mixture (Fig. 8B). These results indicated that the $45 \mathrm{kDa}$ sperm acrosin in the plasma membrane of ejaculated sperm supports the binding of sperm to the PVM in quail fertilization.

\section{Discussion}

In this study, we produced an antibody library against quail sperm membrane components, and the mAb 19A16A13, which strongly inhibits sperm perforation

Table 1 Summary of tandem mass spectrometry analysis of antigen protein in Japanese quail . $^{\text {. }}$

\begin{tabular}{|c|c|c|c|c|c|c|c|}
\hline $\begin{array}{l}\text { Amino acid } \\
\text { nos }\end{array}$ & Sequence & $\begin{array}{c}\mathrm{m} / \mathbf{z} \\
\text { observed }\end{array}$ & Charge & $\mathbf{M r}(\mathrm{calc})$ & $\begin{array}{l}\text { MASCOT } \\
\text { (score) }\end{array}$ & $\begin{array}{c}\text { PEAKS } \\
(\text { score } \%)\end{array}$ & $\begin{array}{l}\text { SPIDER } \\
(\text { score \#) }\end{array}$ \\
\hline $56-64$ & QLGPEAVVR & 484.8127 & $2+$ & 967.5451 & 34.49 & 99.4 & 32.22 \\
\hline $69-77$ & VIPHEYYHR & 405.2365 & $3+$ & 1212.6040 & 54.82 & 99.4 & 39.95 \\
\hline $71-77$ & PHEYYHR & 501.2652 & $2+$ & 1000.4515 & - & - & 29.85 \\
\hline $95-110$ & $\mathrm{C}(+57.02) \mathrm{SYYIELAC}(+57.02) \mathrm{VPDNSVR}$ & 973.5128 & $2+$ & 1944.8708 & - & - & 53.43 \\
\hline $111-128$ & $\begin{array}{l}\text { VSELTDC }(+57.02) \text { YVAGWGHM }(+15.99) \\
\text { GM }(+15.99) \mathrm{R}\end{array}$ & 701.0219 & $3+$ & 2099.8863 & 8 & 38.1 & - \\
\hline $129-138$ & SLQEYVEPYR & 642.3597 & $2+$ & 1282.6194 & 44.28 & 99.4 & 40.1 \\
\hline $192-208$ & DKTADYFWLIGVTSWGK & 994.0816 & $2+$ & 1985.9888 & 17 & 12.0 & - \\
\hline $192-208$ & DKTADYFWLIGVTSWGK & 663.0593 & $3+$ & 1985.9888 & 33.9 & 27.3 & - \\
\hline $194-208$ & TADYFWLIGVTSWGK & 872.5177 & $2+$ & 1742.8667 & 27.52 & 31.6 & - \\
\hline $213-226$ & AQQPGVYASTQYFR & 808.4503 & $2+$ & 1614.7790 & 59.56 & 99.4 & 48.92 \\
\hline
\end{tabular}

$C(+57.02)$, carbamidomethylation of $C$; $M(+15.99)$, oxidation of $M$.

${ }^{a}$ All peaks are monoisotopic. 
A

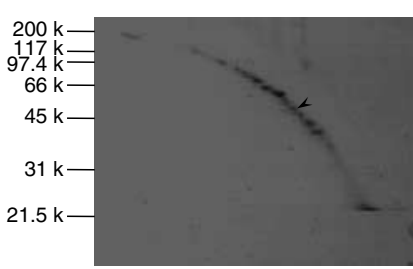

C

1 WPWIVSLOST WYVGTGHICG GSLITPOWVL TAAHCFDHAS PDTPWHVVIC 51 GHNLKQLGPE AVVRSVVRVI PHEYYHRDSM ANDIALLELD QPVQCSYYIE 101 LACVPDNSVR VSELTDCYVA GWGHMGMRSL QEYVEPYRVL QEAKVHLIDL 151 NICNSSHWYA GAIHSHNICA GYPOGGIDTC OGDSGGPLMC KDKTADYFWL 201 IGVTSWGKGC GRAOOPGVYA STOYFRNWIL VOMGLLPAEA PTSTPYXVYV 251 TTSYQRPXXK PTYSSPFRPC PFPHQKLLDF FNMLQELLQS LGGKKARLAA

Figure $5 \mathrm{MS} / \mathrm{MS}$ analysis of the antigen of mAb 19A16A13. SPML (40 $\mu$ g protein) was separated by two-dimensional SDS-PAGE, and the proteins were detected with $\mathrm{CBB}(\mathrm{A})$ or western blotting using $\mathrm{mAb}$ 19A16A13 (B). The position of the $45 \mathrm{kDa}$ antigen spot is shown (arrow in panel $\mathrm{A}$ ). (C) The deduced amino acid sequence of quail acrosin (GenBank accession number ABQ40000). The peptide fragments detected by MS/MS analysis are shown as bold letters.

of the PVM in vitro, was obtained. From the data of the MS/MS analysis, we showed that quail acrosin to be the antigen reactive to the mAb. To our knowledge, this is the first direct evidence showing that the sperm acrosin plays an essential role in avian fertilization.

For the penetration of PVM, it is assumed that sperm have to bind to the PVM and undergo an AR, digest the PVM protein, and penetrate it. Because the $\mathrm{mAb}$, which recognizes the $45 \mathrm{kDa}$ quail acrosin, can inhibit hole formation in the PVM (Fig. 1), the $45 \mathrm{kDa}$ acrosin has a pivotal role in fertilization. In chickens and turkeys, the extracts prepared from the ejaculated sperm contain amidase activity based on the potency to degrade gelatin as well as $N$ - $\alpha$-benzoyl-DL-arginine- $p$-nitroanilide as a substrate (Ho \& Meizel 1975, Brown \& Hartree 1976, Richardson et al. 1988, Froman 1989, Richardson et al. 1992). This sperm amidase in the extracts is considered to be a trypsin-like protease, since the enzyme reaction was inhibited by aprotinin, SBTI, and benzamidine, which inhibit the proteolytic activity of trypsin and the related proteolytic enzymes (Richardson et al. 1992). Quite recently, this amidase was isolated from turkey sperm by gel filtration and directly identified as acrosin by $\mathrm{N}$-terminal Edman sequencing (Slowinska et al. 2010). These reports suggest that the sperm acrosin functions as a lytic agent in the process of sperm penetration by hydrolysis of the PVM in fertilization, although the specific substrate in the PVM has not yet been identified.

In our results, the $45 \mathrm{kDa}$ acrosin showed protease activity that was inhibited by SBTI and leupeptin; however, the hydrolysis of gelatin was not affected by the addition of the mAb 19A16A13 or its Fab fragment (Fig. 6). We did not deny the involvement of sperm acrosin in the process of PVM decomposition, because the epitope of the mAb includes the sugar moiety of the sperm acrosin by periodate oxidation (Fig. 2B). In mice, the active site of acrosin is a catalytic triad of His, Asp, and Ser located in the heavy chain in the molecule (Honda et al. 2002), and the contribution of the sugar moiety to the enzymatic activity has not been demonstrated. Considering these observations along with our results, we suppose that the active site and substratebinding site of quail acrosin are not blocked by the mAb 19A16A13.

More importantly, our results demonstrated that the $45 \mathrm{kDa}$ sperm acrosin interacts with PVM components immobilized on a PVDF membrane (Fig. 7). In addition, the $\mathrm{mAb}$ has potency to directly inhibit sperm binding to the PVM (Fig. 8). From the evidence demonstrated here, the $45 \mathrm{kDa}$ acrosin is suggested to mediate the sperm-PVM binding in quail fertilization. In mice, ZP2 binds to proacrosin-null sperm considerably less effectively than wild-type sperm, and the binding of proacrosin to ZP2 is mediated by a strong ionic interaction between polysulfate groups on ZP2 and basic residues on an internal proacrosin peptide (Howes et al. 2001), resulting to conclude that the ZP2-proacrosin interaction is important for the retention of acrosome reacted sperm on the ZP surface. In case of ascidian sperm, paired basic amino acid residues of acrosin are reported to play a key role in the binding of acrosin to the vitelline coat (Kodama et al. 2001). Because ascidian acrosin is released from sperm into the surrounding seawater, acrosin is suggested to be also involved in the process of sperm penetration through the vitelline coat (Kodama et al. 2001).

In our results, since the $45 \mathrm{kDa}$ acrosin localized both on the surface of the sperm head and in the acrosomal matrix, based on the immunoelectron microscopic observations (Fig. 4), the $45 \mathrm{kDa}$ acrosin is suggested to

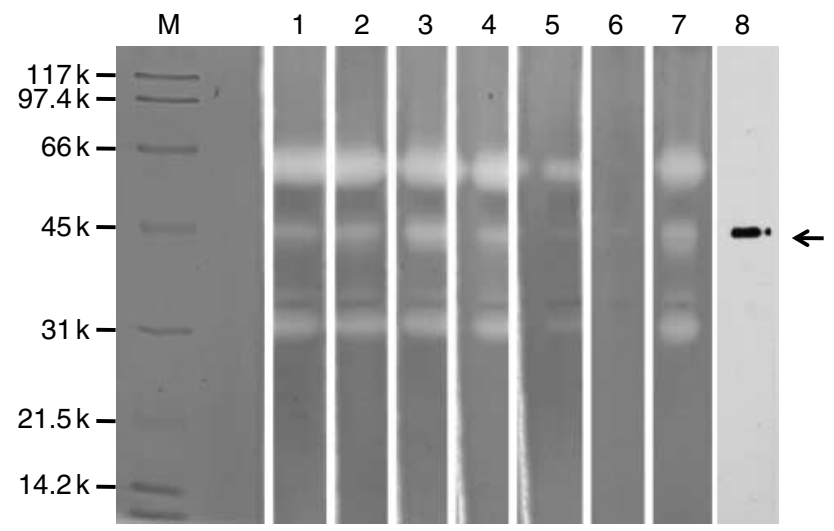

Figure 6 Zymography of SPML. SPML (10 $\mu$ g protein) was separated with a SDS-PAGE gel-containing gelatin, and the gel strips were cut along the lane casting. Each gel strip was then incubated with mouse $\operatorname{lgG}$ (lane 1), mAb 19A16A13 (lane 2), Fab fragment of the mAb (lane 3), PMSF (lane 4), SBTI (lane 5), leupeptin (lane 6), or bestatin (lane 7). One additional strip was processed for western blotting with $\mathrm{mAb}$ 19A16A13 (lane 8). The position of the $45 \mathrm{kDa}$ acrosin is shown by an arrow on the right side of the figure. Results shown are representative of three repeated experiments. 


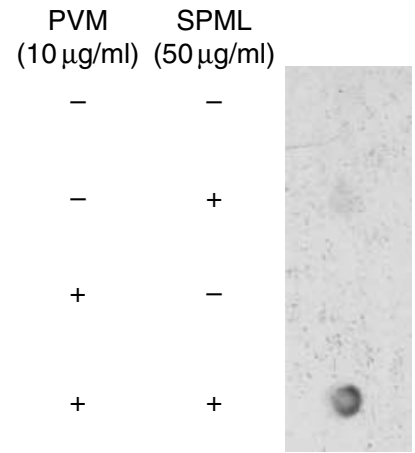

Figure 7 Dot blot assay with mAb 19A16A13. SDS-solubilized PVM or lysis buffer alone was dot blotted onto a PVDF sheet by the aid of a dot blotter and then blocked with N101 blocking reagent. Each dot was incubated with SPML ( $50 \mu \mathrm{g} / \mathrm{ml}$ ) or lysis buffer only as a control to bind the sperm membrane components in SPML. The dots were incubated with mAb 19A16A13 and then with a HRP-coupled secondary antibody. The PVDF sheet was visualized with an ECL detection system. Results shown are representative of three repeated experiments.

be involved in the primary binding of acrosome-intact sperm to the PVM in addition to the hydrolysis of the PVM. We were not able to identify the binding partner of the $45 \mathrm{kDa}$ acrosin in the PVM, because we failed to detect the specific binding signal of the sperm acrosin to the PVM lysate by far-western blot analysis (data not shown). Although we did not pursue the discrepancy of the results between the dot blot assay and far-western blotting, we assume that the interaction of the $45 \mathrm{kDa}$ acrosin with the PVM is not simply mediated via a single molecule but supported by a complex of PVM proteins. Actually, we previously reported that the interaction of ZP1 and ZP3 (Ohtsuki et al. 2004, Sasanami et al. 2006) as well as that of ZP2 and ZP3 (Kinoshita et al. 2010) play a role in the formation of the PVM during follicular development in quail. Moreover, we found that the sperm acrosin contains disulfide-bonded threedimensional arrangement with a modification of sugar moiety in the molecule, though a role of these structures for the sperm-egg interaction in fertilization remains to be studied (Fig. 2). Further experiments will be needed to elucidate the binding machinery of the acrosin and the PVM in fertilization.

Baba et al. (1994) demonstrated that acrosin-null male mice produced normal sperm in motility and were fertile; therefore, acrosin is not essential for fertilization, at least in the mouse. Although we are not able to draw a conclusion about whether the sperm acrosin is essential for quail fertilization due to the limitation of the technology (i.e. lack of the gene knockout technique in birds), Adham et al. (1997) reported that in an in vitro fertilization assay with equal numbers of acrosin-knockout $(-/-)$ and wild-type $(+/+)$ sperm present in the medium, all the embryos derived from the fertilized eggs were of the $(+/+)$ genotype. Their finding might indicate the presence of unknown mechanisms for sperm competition related to the function of acrosin in the sperm-egg recognition process. Thus, sperm acrosin is not essential, but plays a critical role in fertilization in mice. Actually, we know at present that acrosin is responsible for the dispersal of the acrosomal contents during AR (Yamagata et al. 1998). Our current findings in Japanese quail also suggest the importance of sperm acrosin for fertilization since this amidase is responsible for the process of sperm-egg binding.

In conclusion, this investigation provides the first evidence that the sperm acrosin is responsible for the binding of sperm to the PVM in quail fertilization. Further studies are required to elucidate whether the sperm acrosin is involved in other events of fertilization such as the induction of $A R$, penetration of the PVM, or the membrane fusion of gametes.

\section{Materials and Methods}

\section{Animals and tissue preparation}

Male and female Japanese quail (Coturnix japonica), 15-30 weeks of age (Kato-farm, Toyohashi, Japan), were maintained individually under a photoperiod of $14 \mathrm{~h}$ light: $10 \mathrm{~h}$ darkness (with the light on at $0500 \mathrm{~h}$ ) and were provided with water and a commercial diet (Tokai-Hokuriku Nosan, Chita, Japan) ad libitum. The female animals were decapitated and the largest preovulatory follicles were dissected. The granulosa layer from the largest preovulatory follicles was isolated as a sheet of granulosa cells sandwiched between the PVM and basal laminae, as described previously (Gilbert et al. 1977). The PVM was isolated according to a procedure described by Sasanami et al. (2002). The PVM was then dissolved in 1\% SDS $(\mathrm{w} / \mathrm{v})$ buffered at $\mathrm{pH} 6.8$ with $70 \mathrm{mmol} / \mathrm{l}$ Tris- $\mathrm{HCl}$ overnight at room temperature. After centrifugation at $10000 \mathrm{~g}$ for $10 \mathrm{~min}$, the supernatants were served as PVM lysates and the protein concentration of the lysates was measured using a BCA protein assay kit (Pierce, Rockford, IL, USA). A proctodeal gland secretion was obtained manually from male quail as meringuelike foam. This foam was then centrifuged at $10000 \mathrm{~g}$ for $10 \mathrm{~min}$, and the supernatants collected were stored as proctodeal gland secretion at $-80^{\circ} \mathrm{C}$ until use.
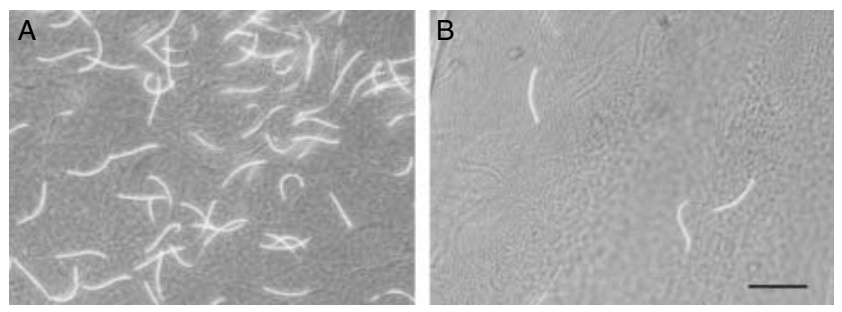

Figure 8 Effects of mAb 19A16A13 on the interaction of ejaculated sperm and PVM. Ejaculated sperm were incubated with PVM in the presence of $20 \mu \mathrm{g} / \mathrm{ml}$ of mAb 19A16A13 (panel B) or mouse IgG (panel A). After washing with PBS, the PVM was spread on glass slides, fixed with formalin and observed under a fluorescence microscope. The sperm nuclei were stained with DAPI. Representative photographs of two independent experiments are shown; bar $=20 \mu \mathrm{m}$. 
All the experimental procedures for the use and the care of animals in this study were approved by the Animal Care Committee of Shizuoka University (approval number, 22-12).

\section{Semen collection and preparation}

Ejaculated semen was obtained from male quail before mating according to the procedure of Kuroki \& Mori (1997). Semen obtained from two to three males was suspended in Hanks' balanced salt solution (HBSS) containing $1.25 \mathrm{mmol} / \mathrm{l}$ of $\mathrm{CaCl}_{2}$ and $0.1 \%(\mathrm{v} / \mathrm{v})$ of proctodeal gland secretion. We added proctodeal gland secretion to the incubation mixture since it inhibits an agglutination of quail sperm. The concentrations of sperm were measured with a hemocytometer and the sperm viabilities were determined using the LIVE/DEAD sperm viability kit according to the manufacturer's instructions (Molecular Probes, Eugene, OR, USA). In all the experiments, sperm were incubated at $39^{\circ} \mathrm{C}$.

\section{Production of $M A B$}

Ejaculated sperm were washed three times with PBS by repeated centrifugation at $800 \mathrm{~g}$ for $5 \mathrm{~min}$, and the sperm were then suspended in homogenization buffer containing $110 \mathrm{mmol} / \mathrm{I} \mathrm{NaCl}, 1 \mathrm{mmol} / \mathrm{I}$ EDTA, $1 \mathrm{mmol} / \mathrm{I} \mathrm{PMSF}$, and $50 \mathrm{mmol} / / \mathrm{l}$ Tris- $\mathrm{HCl}(\mathrm{pH} 7.4)$ for disruption with an ultrasonic disruptor at medium power for $10 \mathrm{~s}$ on ice. The sonication was performed for ten times. The homogenates were centrifuged at $10000 \mathrm{~g}$ for $10 \mathrm{~min}$ for the removal of cellular debris, and the supernatant was ultracentrifuged at $100000 \mathrm{~g}$ for $1 \mathrm{~h}$ at $4{ }^{\circ} \mathrm{C}$. The plasma membrane fraction obtained as a precipitate was dissolved in $0.8 \mathrm{ml}$ of lysis buffer (homogenization buffer supplemented with $250 \mu \mathrm{mol} / \mathrm{l}$ digitonin and $1 \%(\mathrm{w} / \mathrm{v})$ Nonidet P-40 (Wako Pure Chemicals, Tokyo, Japan)) and sonicated as described earlier. After centrifugation at $20000 \mathrm{~g}$ for $10 \mathrm{~min}$, the supernatant, referred to as SPML, was divided into aliquots and stored at $-80{ }^{\circ} \mathrm{C}$ until use.

Immunization of mice with sperm plasma membrane, cell fusion of lymphocytes from immunized mice with myeloma PAI, and establishment of an antibody library against sperm plasma membrane components were carried out as described previously (Nagai et al. 2009).

The mAb 19A16A13-producing hybridoma cloned by screening as described in the following section (in vitro assay for sperm-egg interaction) was cultured in $300 \mathrm{ml}$ of HAT-supplemented medium, and the mAb 19A16A13 (IgG1 isotype) was purified from the conditioned medium with a Protein A-coupled Affi-gel (Bio-Rad Laboratories) column according to the manufacturer's protocol. Fab fragments of the purified $\mathrm{mAb}$ were prepared with a Pierce Fab preparation kit (Pierce).

\section{In vitro assay for sperm-egg interaction}

To observe the inhibitory activity of each culture supernatant against the sperm penetration of the PVM, a piece of PVM, $\sim 8 \mathrm{~mm}$ in diameter, was incubated in a micro test tube with $0.5 \mathrm{ml}$ of sperm suspension at $1 \times 10^{7}$ sperm $/ \mathrm{ml}$ in HBSS at $39{ }^{\circ} \mathrm{C}$ for $30 \mathrm{~min}$ in the presence or absence of culture supernatant. After $30 \mathrm{~min}$ of incubation, the reaction was terminated by placing the tube on ice, and the PVM was washed three times with ice-cold PBS. The PVM was transferred onto a glass slide and stained with Schiff's reagent after fixation with $3.7 \%(\mathrm{v} / \mathrm{v})$ formaldehyde in PBS. The number of holes formed on the PVM in the $\times 40$ field was counted under a light microscope (BX 51, Olympus Optics, Tokyo, Japan). At least five areas were randomly selected for enumeration of perforations.

For the observation of the sperm binding to the PVM, $2 \mu \mathrm{g} / \mathrm{ml}$ pertussis toxin was added to the reaction mixture during the sperm-PVM incubation, which was previously reported to inhibit sperm AR in quail (Sasanami et al. 2007). After the incubation, the nuclei of the adherent sperm were stained with 4', 6-diamidino-2-phenylindole (DAPI) after fixation, and the number of sperm attached to the PVM was observed under a fluorescence microscope (BX51).

\section{Gel electrophoresis and western blot analysis}

SDS-PAGE under non-reducing or reducing conditions was carried out according to Laemmli (1970) using 12 and 5\% (w/v) polyacrylamide gel for resolving and stacking respectively. For-western blotting, proteins separated by SDS-PAGE were electrotransferred to a PVDF membrane (Immobilon-P, Millipore, Bedford, MA, USA; Matsudaira 1987). The membrane incubated with mAb 19A16A13 $(10 \mu \mathrm{g} / \mathrm{ml})$ followed by HRP-conjugated anti-mouse IgG (Cappel, Durham, NC, USA) as a secondary antibody was visualized by means of a chemiluminescent technique (Amersham Pharmacia Biotech).

For periodate oxidation of SPML proteins, a PVDF strip electrotransferred with SPML was oxidized for $20 \mathrm{~min}$ with $10 \mathrm{mmol} / \mathrm{l}$ sodium metaperiodate in $100 \mathrm{mmol} / \mathrm{l}$ acetate buffer (pH 5.5) in the dark. After brief rinsing with PBS, the aldehyde group formed was reduced with $100 \mathrm{mmol} / \mathrm{l}$ sodium borohydride in PBS for 15 min. After washing with PBS, the strip was subjected to immunoblotting as described earlier.

\section{Zymography}

SPML $(10 \mu \mathrm{g}$ protein) was separated with an SDS-PAGE gel containing $0.1 \%(\mathrm{w} / \mathrm{v})$ gelatin according to the procedure described in the previous report (Heussen \& Dowdle 1980). After the electrophoresis, the gel strips were excised along the lane casting, and each gel was incubated with $0.1 \mathrm{~mol} / \mathrm{l}$ glycine buffer ( $\mathrm{pH}$ 8.0) containing $20 \mu \mathrm{g} / \mathrm{ml}$ mouse $\mathrm{IgG} 1,20 \mu \mathrm{g} / \mathrm{ml}$ $\mathrm{mAb} 19 \mathrm{~A} 16 \mathrm{~A} 13,40 \mu \mathrm{g} / \mathrm{ml}$ Fab fragment of mAb 19A16A13, $1 \mathrm{mmol} / \mathrm{I}$ PMSF, $50 \mu \mathrm{g} / \mathrm{ml} \mathrm{SBTI}, 0.5 \mu \mathrm{g} / \mathrm{ml}$ leupeptin, or $40 \mu \mathrm{g} / \mathrm{ml}$ bestatin at $4{ }^{\circ} \mathrm{C}$ for $1 \mathrm{~h}$ with gentle agitation. After the incubation, the gel strips were incubated at $37^{\circ} \mathrm{C}$ for $3 \mathrm{~h}$ to promote the enzyme reaction. After the reaction, gel strips were stained with $\mathrm{CBB}$, and the halo formation in the gels was observed.

\section{MS/MS analysis}

SPML (40 $\mu$ g protein) was separated by SDS-PAGE as described earlier and the proteins were visualized by CBB staining. The gel strip was excised along with the lane casting and incubated 
with Laemmli's sample buffer (Laemmli 1970) without 2-mercaptoethanol for $15 \mathrm{~min}$. After the incubation, the gel strip was loaded on an SDS-PAGE gel, and the proteins were again separated with SDS-PAGE as described earlier. After the SDS-PAGE, the proteins were electrotransferred to a PVDF membrane, and the immunoreactive spot with mAb 19A16A13 was detected as described earlier. After the detection, the PVDF membrane was washed three times with PBS and stained with CBB. After the staining, the X-ray film already developed to have the chemiluminescent signal was laid on the stained membrane, allowing us to identify the antigen spot. The gel strip containing SPML $(40 \mu \mathrm{g})$ was separated with another SDS-PAGE gel, stained with CBB and a piece of the gel $\left(\sim 1 \times 1 \mathrm{~mm}^{2}\right)$ containing antigen protein identified as described earlier was excised. The proteins in the gel were reduced with $10 \mathrm{mM}$ dithiothreitol in $50 \mathrm{mM}$ ammonium bicarbonate, S-alkylated cysteine with $55 \mathrm{mM}$ iodoacetamide in $50 \mathrm{mM}$ ammonium bicarbonate and digested with $10 \mathrm{ng} / \mu \mathrm{l}$ of sequence grade trypsin (Promega Corporation) at $37^{\circ} \mathrm{C}$ overnight. The peptides were extracted from the gel with $50 \%(\mathrm{v} / \mathrm{v})$ acetonitrile (ACN) and 5\% (v/v) formic acid, and concentrated using a centrifugal evaporator. The peptide solution was diluted with $10 \mu \mathrm{l}$ of $0.3 \%(\mathrm{v} / \mathrm{v})$ formic acid to be suitable for liquid chromatography-MS/MS (LC-MS/MS) analysis.

LC-MS/MS analysis was performed by a linear ion trap timeof-flight mass spectrometer (LIT-TOF MS), NanoFrontier eLD (Hitachi High-Technologies Corporation) coupled to a nanoflow HPLC, NanoFrontier nLC (Hitachi High-Technologies Corporation). Peptides extracted from the gel were trapped and desalted with a C18 monolith trap column $(0.05 \mathrm{~mm}$ ID $\times 150 \mathrm{~mm}$ long; Hitachi High-Technologies Corporation) and then loaded onto a MonoCap C18 Fast-flow column (0.05 mm ID $\times 150$ mm long; GL Sciences, Inc., Tokyo, Japan) and eluted with a linear gradient from 2 to $40 \%$ solvent $B$ in $60 \mathrm{~min}$ at a flow rate of $200 \mathrm{nl} / \mathrm{min}$. Solvent A was $2 \% \mathrm{ACN}$ and $0.1 \%$ formic acid, and solvent $\mathrm{B}$ was $98 \% \mathrm{ACN}$ and $0.1 \%$ formic acid. The eluent was ionized with a nanoelectrospray ionization source equipped with an uncoated SilicaTip (New Objective, Woburn, MA, USA) and analyzed with a LIT-TOF MS. Mass spectra were obtained in positive ion mode at scan mass range $\mathrm{m} / \mathrm{z}$ 200-2000. MS/MS spectra were generated by collision-induced dissociation in the linear ion trap.

To identify the antigen protein, we converted the MS and MS/MS data to an MGF file using a NanoFrontier eLD Data Processing software (Hitachi High-Technologies Corporation) and analyzed the data with MASCOT MS/MS Ions Search (Perkins et al. 1999; http://www.matrixscience.com/) using the following parameters: database, NCBInr; enzyme, trypsin; missed cleavages, 3; taxonomy, all entries; fixed modifications, carbamidomethyl $(\mathrm{C})$; variable modifications, oxidation (HW) and oxidation $(\mathrm{M})$; peptide tolerance, $0.2 \mathrm{Da}$; MS/MS tolerance, $0.2 \mathrm{Da}$; Peptide charge, $1+, 2+$, and $3+$; Instrument, ESI-TRAP. To confirm the reliability of the result of the protein identification by MASCOT, we also used the de novo sequencing and protein identification software PEAKS STUDIO (Bioinformatics Solutions, Inc., Waterloo, ON, Canada; Ma et al. 2003) and the sequence tag search tool SPIDER (Han et al. 2005).

\section{Immunofluorescence microscopy}

Ejaculated sperm were diluted to $1 \times 10^{7} / \mathrm{ml}$ and fixed in $3.7 \%(\mathrm{v} / \mathrm{v})$ formaldehyde in PBS at room temperature for $10 \mathrm{~min}$. The fixed sperm were smeared on poly-L-lysine coated microscope slides. After air drying, the slides were washed with PBS for $5 \mathrm{~min}$, and the cells were incubated with PBS containing $1 \%$ BSA and $10 \%$ normal goat serum for $1 \mathrm{~h}$ for blocking. The cells were then incubated with mAb 19A16A13 $(10 \mu \mathrm{g} / \mathrm{ml})$ or mouse $\operatorname{lgG}(10 \mu \mathrm{g} / \mathrm{ml})$ for $2 \mathrm{~h}$ at $4{ }^{\circ} \mathrm{C}$. After washing with PBS, they were incubated with Texas redconjugated sheep anti-mouse IgG (1:200, Cappel) for $1 \mathrm{~h}$ at $4{ }^{\circ} \mathrm{C}$. After washing with PBS they were embedded in glycerol and examined under a fluorescence microscope equipped with an interference contrast apparatus with a $40 \times$ objective (BX 51, Olympus Optics, Tokyo, Japan).

\section{Immunoelectron microscopy}

Ejaculated sperm embedded in $3 \%(\mathrm{w} / \mathrm{v})$ agarose were fixed with $2.5 \%(\mathrm{v} / \mathrm{v})$ glutaraldehyde in $0.1 \mathrm{~mol} / \mathrm{ml}$ cacodylate buffer ( $\mathrm{pH}$ 7.4) overnight at $4{ }^{\circ} \mathrm{C}$. The specimens were embedded in Lowicryl $\mathrm{K}_{4} \mathrm{M}$ resin (Polysciences, Warrington, PA, USA). Thin sections were first treated with mAb 19A16A13 $(10 \mu \mathrm{g} / \mathrm{ml})$ or mouse $\operatorname{lgG}(10 \mu \mathrm{g} / \mathrm{ml})$, and then with a goldconjugated goat antiserum against mouse $\operatorname{IgG}(1: 30 ; \mathrm{E}-\mathrm{Y}$ Laboratories, San Mateo, CA, USA). They were stained with uranyl acetate and observed with a model $\mathrm{H}-8000$ electron microscope (Hitachi).

\section{Dot blot assay}

The dot blot assay was performed according to Kubo et al. (2010). A PVDF sheet (Immobilon-P; Millipore) wetted with methanol and then with PBS was set in a dot blotter (Bio-Rad Laboratories), and $100 \mu \mathrm{l}$ of PVM lysate at $10 \mu \mathrm{g}$ protein $/ \mathrm{ml}$ was added to each well. After 20 min, the PVM solution was removed by suction, and the wells were washed by suction with PBS three times. Thereafter, the solution in the well was externally aspirated out for disposal. The wells were blocked for $30 \mathrm{~min}$ with blocking reagent N101 (NOF Corporation, Tokyo, Japan). After blocking, the wells were rinsed once each with PBS and then with lysis buffer, and $100 \mu \mathrm{l}$ of SPML at $50 \mu \mathrm{g}$ protein $/ \mathrm{ml}$ was added to each well, and the wells were incubated for $30 \mathrm{~min}$. After the incubation, the wells were washed twice with lysis buffer and then once with PBS and were again blocked with the blocker in the same manner. After wells were washed with PBS, $100 \mu$ l of culture supernatant was added to each well and the wells were incubated for $30 \mathrm{~min}$. The wells were washed three times with PBS containing $0.1 \%$ $(\mathrm{w} / \mathrm{v})$ Tween 20, and the bound antibodies were labeled for $30 \mathrm{~min}$ with $50 \mu \mathrm{l} /$ well of peroxidase-conjugated anti-mouse IgG (GE Healthcare, Tokyo, Japan) 5000-fold diluted with 5\% $(\mathrm{w} / \mathrm{v})$ skim milk in PBS. The wells were washed three times with $0.1 \%(\mathrm{w} / \mathrm{v})$ Tween 20 in PBS, and the PVDF sheet removed from the blotter was washed again with vigorous shaking three times and then subjected to a chemiluminescent detection system as described earlier. 


\section{Statistical analysis}

Data in Fig. 1C were analyzed for significant differences using ANOVA, and means were compared by Tukey's multiple range test. For Fig. 1D, data were analyzed by the student's $t$-test. A $P$ value of $<0.05$ denoted the presence of a statistically significant difference.

\section{Declaration of interest}

The authors declare that there is no conflict of interest that could be perceived as prejudicing the impartiality of the research reported.

\section{Funding}

This work was supported in part by financial support from Grant-in-Aid for Challenging Exploratory Research (21658100 to $\mathrm{T}$ Sasanami), Grant-in-Aid for Scientific Research on Innovative Areas (22112509 to T Sasanami), and The Sumitomo Foundation (101069 to T Sasanami).

\section{Acknowledgements}

The authors are grateful to $\mathrm{Mr} \mathrm{T}$ Sakakibara and Dr K Yoshimatsu for technical assistance.

\section{References}

Adham IM, Nayernia K \& Engel W 1997 Spermatozoa lacking acrosin protein show delayed fertilization. Molecular Reproduction and Development 46 370-376. (doi:10.1002/(SICI)1098-2795(199703)46:3 $<370::$ AID-MRD16>3.0.CO;2-2)

Baba T, Azuma S, Kashiwabara S \& Toyoda Y 1994 Sperm from mice carrying a targeted mutation of the acrosin gene can penetrate the oocyte zona pellucida and effect fertilization. Journal of Biological Chemistry $26931845-31849$.

Bork P \& Sander C 1992 A large domain common to sperm receptors (ZP2 and ZP3) and TGF- $\beta$ type III receptor. FEBS Letters 300 237-240. (doi:10.1016/0014-5793(92)80853-9)

Brown CR \& Hartree EF 1976 Comparison of neutral proteinase activities in cock and ram spermatozoa and observations on a proacrosin in cock spermatozoa. Journal of Reproduction and Fertility 46 155-164. (doi:10.1530/jrf.0.0460155)

Ensslin MA \& Shur BD 2003 Identification of mouse sperm SED1, a bimotif EGF repeat and discoidin-domain protein involved in sperm-egg binding. Cell 114 405-417. (doi:10.1016/S0092-8674(03)00643-3)

Florman HM \& Ducibella T 2006 Fertilization in mammals. In Physiology of Reproduction, vol 1, 3 edn, pp 55-112. Ed JD Neill. St Louis: Elsevier Academic Press.

Froman DP 1989 Chicken acrosin: extraction and purification. Poultry Science 69 812-817.

Ganguly A, Sharma RK \& Gupta SK 2008 Bonnet monkey (Macaca radiata) ovaries, like human oocytes, express four zona pellucida glycoproteins. Molecular Reproduction and Development 75 156-166. (doi:10.1002/ mrd.20808)

Gilbert AB, Evans AJ, Perry MM \& Davidson MH 1977 A method for separating the granulosa cells, the basal lamina and the theca of the preovulatory ovarian follicle of the domestic fowl (Gallus domesticus). Journal of Reproduction and Fertility 50 179-181. (doi:10.1530/jrf.0. 0500179)

Goudet G, Mugnier S, Callebaut I \& Monget P 2008 Phylogenetic analysis and identification of pseudogenes reveal a progressive loss of zona pellucida genes during evolution of vertebrates. Biology of Reproduction 78 796-806. (doi:10.1095/biolreprod.107.064568)
Han Y, Ma B \& Zhang K 2005 SPIDER: software for protein identification from sequence tags containing de novo sequencing error. Journal of Bioinformatics and Computational Biology 3 697-716. (doi:10.1142/ S0219720005001247)

Heussen C \& Dowdle EB 1980 Electrophoretic analysis of plasminogen activators in polyacrylamide gels containing sodium dodecyl sulfate and copolymerized substrates. Analytical Biochemistry 102 196-202. (doi:10.1016/0003-2697(80)90338-3)

Ho JJL \& Meizel S 1975 Multiple molecular forms of avian acrosin: differences in their kinetic properties. FEBS Letters 56 115-119. (doi:10. 1016/0014-5793(75)80123-2)

Honda A, Siruntawineti J \& Baba T 2002 Role of acrosomal matrix proteases in sperm-zona pellucida interactions. Human Reproduction Update 8 405-412. (doi:10.1093/humupd/8.5.405)

Hoodbhoy T, Joshi S, Boja ES, Williams SA, Stanley P \& Dean J 2005 Human sperm do not bind to rat zonae pellucidae despite the presence of four homologous glycoproteins. Journal of Biological Chemistry $\mathbf{2 8 0}$ 12721-12731. (doi:10.1074/jbc.M413569200)

Horrocks AJ, Stewart S, Jackson L \& Wishart GJ 2000 Induction of acrosomal exocytosis in chicken spermatozoa by inner perivitellinederived N-linked glycans. Biochemical and Biophysical Research Communications 278 84-89. (doi:10.1006/bbrc.2000.3766)

Howes E, Pascall JC, Engel W \& Jones R 2001 Interactions between mouse ZP2 glycoprotein and proacrosin; a mechanism for secondary binding of sperm to the zona pellucida during fertilization. Journal of Cell Science 114 4127-4136.

Ikawa M, Inoue N \& Okabe M 2008 Mechanisms of sperm-egg interactions emerging from gene-manipulated animals. International Journal of Developmental Biology 52 657-664. (doi:10.1387/ijdb. 072529mi)

Izquierdo-Rico MJ, Jimenez-Movilla M, Llop E, Perez-Oliva AB, Ballesta J, Gutierrez-Gallego R, Jimenez-Cervantes C \& Aviles M 2009 Hamster zona pellucida is formed by four glycoproteins: ZP1, ZP2, ZP3, and ZP4. Journal of Proteome Research 8 926-941. (doi:10.1021/ pr800568x)

Kim E, Baba D, Kimura M, Yamashita M, Kashiwabara S \& Baba T 2005 Identification of a hyaluronidase, hyal5, involved in penetration of mouse sperm through cumulus mass. PNAS 102 18028-18033. (doi:10.1073/ pnas.0506825102)

Kinoshita M, Rodler D, Sugiura K, Matsushima K, Kansaku N, Tahara K, Tsukada A, Ono H, Yoshimura T, Yoshizaki N et al. 2010 Zona pellucida protein ZP2 is expressed in the oocyte of Japanese quail (Coturnix japonica). Reproduction 139 359-371. (doi:10.1530/REP-090222)

Kodama E, Baba T, Yokosawa H \& Sawada H 2001 cDNA cloning and functional analysis of ascidian sperm. Journal of Biological Chemistry 276 24594-24600. (doi:10.1074/jbc.M011370200)

Kubo H, Shiga K, Harada Y \& Iwao Y 2010 Analysis of a sperm surface molecule that binds to a vitelline envelope component of Xenopus laevis eggs. Molecular Reproduction and Development 77 728-735. (doi:10. 1002/mrd.21211)

Kuroki M \& Mori M 1997 Binding of spermatozoa to the perivitelline layer in the presence of a protease inhibitor. Poultry Science 76 748-752.

Laemmli UK 1970 Cleavage of structural proteins during the assembly of the head of bacteriophage $\mathrm{T}_{4}$. Nature 227 680-685. (doi:10.1038/ 227680a0)

Lefievre L, Conner SJ, Salpekar A, Olufowobi O, Ashton P, Pavlovic B, Lenton W, Afnan M, IBrewis IA \& Monk M 2004 Four zona pellucida glycoproteins are expressed in the human. Human Reproduction 19 1580-1586. (doi:10.1093/humrep/deh301)

Lindsay LL, Pwavy TR, Lejano RS \& Hedrick JL 2003 Cross-fertilization and structural comparison of egg extracellular matrix glycoproteins from Xenopus laevis and Xenopus tropicalis. Comparative Biochemistry and Physiology. A, Molecular \& Integrative Physiology 136 343-352. (doi:10. 1016/S1095-6433(03)00169-7)

Litscher ES \& Wassarman PM 2007 Egg extracellular coat proteins: from fish to mammals. Histology and Histopathology 22 337-347.

Ma B, Zhang K, Hendrie C, Liang C, Li M, Doherty-Kirby A \& Lajoie G 2003 PEAKS: Powerful software for peptide de novo sequencing by MS/MS. Rapid Communications in Mass Spectrometry 17 2337-2342. (doi:10. 1002/rcm.1196) 
Matsudaira P 1987 Sequence from picomole quantities of proteins electroblotted onto polyvinylidene difluoride membranes. Journal of Biological Chemistry 262 10035-10038.

Miller DJ, Macek MB \& Shur BD 1992 Complementarity between sperm surface $\beta$ 1, 4-galactosyltransferase and egg-coat ZP3 mediates spermegg binding. Nature 357 589-593. (doi:10.1038/357589a0)

Nagai K, Ishida T, Hashimoto T, Harada Y, Ueno S, Kubo H \& Iwao Y 2009 The sperm-surface glycoprotein, SGP, is necessary for fertilization in the frog, Xenopus leavis. Development, Growth \& Differentiation 51 499-510. (doi:10.1111/j.1440-169X.2009.01112.x)

Ohtsuki M, Hanafy AM, Mori M \& Sasanami T 2004 Involvement of interaction of ZP1 and ZPC in the formation of quail perivitelline membrane. Cell and Tissue Research 318 565-570. (doi:10.1007/ s00441-004-1000-9)

Perkins DN, Pappin DJC, Creasy DM \& Cottrell JS 1999 Probability-based protein identification by searching sequence databases using mass spectrometry data. Electrophoresis 20 3551-3567. (doi:10.1002/(SICI) 1522-2683(19991201)20:18<3551::AID-ELPS3551>3.0.CO;2-2)

Primakoff P, Lathrop W, Woolman L, Cowan A \& Myles D 1988 Fully effective contraception in male and female guinea pigs immunized with the sperm protein ph-20. Nature 335 543-546. (doi:10.1038/335543a0)

Richardson ME, Bodine AB, Froman DP \& Thurston RJ 1988 Turkey acrosin. I. Isolation, purification and partial characterization. Biology of Reproduction 38 645-651. (doi:10.1095/biolreprod38.3.645)

Richardson ME, Korn N, Bodine AB \& Thurston RJ 1992 Kinetic and inhibition studies with turkey acrosin. Poultry Science 71 1789-1793.

Robertson L, Brown HL, Staines HJ \& Wishart GJ 1997 Characterization and application of an avian in vitro spermatozoa-egg interaction assay using the inner perivitelline layer from laid chicken egg. Journal of Reproduction and Fertility 110 205-211. (doi:10.1530/jrf.0.1100205)

Robertson L, Wishart GJ \& Horrocks AJ 2000 Identification of perivitelline $\mathrm{N}$-inked glycans as mediators of sperm-egg interaction in chickens. Journal of Reproduction and Fertility 120 397-403. (doi:10.1530/reprod/ 120.2.397)
Sasanami T, Pan J, Doi Y, Hisada M, Kohsaka T \& Toriyama M 2002 Secretion of egg envelope protein ZPC after C-terminal proteolytic processing in quail granulosa cells. European Journal of Biochemistry 269 2223-2231. (doi:10.1046/j.1432-1033.2002.02880.x)

Sasanami T, Pan J \& Mori M 2003 Expression of perivitelline membrane glycoprotein ZP1 in the liver of Japanese quail (Coturnix japonica) after in vivo treatment with diethylstilbestrol. Journal of Steroid Biochemistry and Molecular Biology 84 109-116. (doi:10.1016/S0960-0760(03) 00008-6)

Sasanami T, Ohtsuki M, Ishiguro T, Matsushima K, Hiyama G, Kansaku N, Doi Y \& Mori M 2006 Zona pellucida domain of ZPB1 controls specific binding of ZPB1 and ZPC in Japanese quail (Coturnix japonica). Cells, Tissues, Organs 183 41-52. (doi:10.1159/000094905)

Sasanami T, Murata T, Ohtsuki M, Matsushima K, Hiyama G, Kansaku N \& Mori M 2007 Induction of sperm acrosome reaction by perivitelline glycoprotein ZP1 in Japanese quail (Coturnix japonica). Reproduction 133 41-49. (doi:10.1530/REP-06-0104)

Slowinska M, Olczak M, Liszewska E, Watorek W \& Ciereszko A 2010 Isolation, characterization and cDNA sequencing of acrosin from turkey spermatozoa. Comparative Biochemistry and Physiology. B, Biochemistry \& Molecular Biology 157 127-136. (doi:10.1016/j.cbpb. 2010.05.011)

Wyburn GM, Aitken RNC \& Johnston HS 1965 The ultrastructure of the zona radiata of the ovarian follicle of the domestic fowl. Journal of Anatomy 99 469-484.

Yamagata K, Murayama M, Okabe M, Toshimori K, Nakanichi T, Kashiwabara S \& Baba T 1998 Acrosin accelerates the dispersal of sperm acrosomal proteins during acrosome reaction. Journal of Biological Chemistry 273 10470-10474. (doi:10.1074/jbc.273.17.10470)

Received 16 April 2011

First decision 20 May 2011

Accepted 3 June 2011 